\title{
Influenza surveillance during the post-pandemic influenza 2010/11 season in Greece, 04 October 2010 to 22 May 2011
}

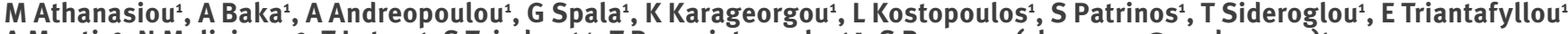 \\ A Mentis' ${ }^{2}$, N Malisiovas ${ }^{3}$, T Lytras ${ }^{1}$, S Tsiodras ${ }^{1,4}$, T Panagiotopoulos ${ }^{1,5}$, S Bonovas (sbonovas@med.uoa.gr) ${ }^{1}$ \\ 1. Hellenic Centre for Disease Control and Prevention, Athens, Greece \\ 2. National Influenza Reference Laboratory for Southern Greece, Hellenic Pasteur Institute, Athens, Greece \\ 3. National Influenza Reference Laboratory for Northern Greece, Medical School, Aristotle University of Thessaloniki, Greece \\ 4. University of Athens Medical School, Athens, Greece \\ 5. National School of Public Health, Athens, Greece
}

Citation style for this article:

Athanasiou M, Baka A, Andreopoulou A, Spala G, Karageorgou K, Kostopoulos L, Patrinos S, Sideroglou T, Triantafyllou E, Mentis A, Malisiovas N, Lytras T, Tsiodras $\mathrm{S}$, Panagiotopoulos T, Bonovas S. Influenza surveillance during the post-pandemic influenza 2010/11 season in Greece, 04 October 2010 to 22 May 2011

Euro Surveill. 2011;16(44):pii=20004. Available online: http://www.eurosurveillance.org/ViewArticle.aspx?Articleld=20004

Article published on 3 November 2011

In this manuscript, we summarise the experience of Greece during the post-pandemic influenza season 2010/11 from 04 October 2010 to 22 May 2011. The spread of the disease and its impact were monitored using multiple surveillance systems, such as sentinel surveillance, virological surveillance and allcause mortality surveillance. We also focus on the characteristics of laboratory-confirmed severe influenza cases who required admission to an intensive care unit (ICU) $(n=368)$, and/or with a fatal outcome $(n=180)$. The influenza-like illness rate reported from sentinel surveillance started rising in early January 2011 and peaked between 31 January and 6 February 2011. The total number of ICU admissions was higher in the post-pandemic influenza season than during the pandemic period causing a lot of pressure on ICUs. The overall population mortality rate due to influenza $A\left(\mathrm{H}_{1} \mathrm{~N}_{1}\right)_{2009}$ was higher than during the pandemic period ( 15.9 vs 13.2 fatal cases per million, $p=0.087)$. Our data suggest that the severity of clinical illness in the first post-pandemic influenza season was comparable or even higher than during the pandemic.

\section{Introduction}

Between May 2009 and May 2010, Greece experienced two waves of influenza $A\left(\mathrm{H}_{1} \mathrm{~N}_{1}\right) 2009$ transmission, a small one in July-August 2009, where cases occurred mostly in areas of the country, which were related to popular tourist destinations, and a larger one that took place all over the country in late autumn, peaking at the end of November 2009. During the pandemic period, there were 18,230 laboratory-confirmed cases, 294 admissions to intensive care units (ICUs) and 149 deaths associated with pandemic influenza virus, a figure that corresponds to one of the highest mortality rates reported in Europe [1-6].
Given the potential for worsening in the clinical severity of influenza during the post-pandemic influenza season, as was the case for previous influenza pandemics [7-9], it was critical to continue surveillance with a focus on severe cases and their clinical characteristics. The United Kingdom (UK) was the first country in Europe to report increased influenza activity as of week 49, 2010, along with an unusual increase in ICU admissions and in the use of extracorporeal membrane oxygenation (ECMO) facilities [10-14].

During the pandemic period, an enhanced ad-hoc surveillance system for severe influenza cases had been in place in Greece $[3,4]$. Following events in the UK, the same system was reactivated in December 2010. It involved direct reporting to the Hellenic Centre for Disease Control and Prevention (HCDCP) of all laboratory-confirmed influenza cases who were admitted to an ICU, and those with a fatal outcome. In addition, investigators made daily follow-up phone calls to the treating physicians of all patients with laboratory-confirmed influenza who were hospitalised in an ICU.

In Greece, influenza is annually monitored through the routine sentinel surveillance system, which became operational in 1999. The sentinel surveillance system, which covers approximately three percent of the total Greek population in the 2010/11 influenza season, provides data representative of the national population, and consists of three separate networks: (i) private physicians, (ii) primary healthcare centres' physicians, and (iii) physicians of the Social Security Institute (IKA). These networks are coordinated by the HCDCP. During the post-pandemic influenza season (2010/11), a total of 240 physicians (general practitioners, internists, or paediatricians) participated in the sentinel surveillance system. Physicians contributing to this system 
reported, on a weekly basis, the number of patients with influenza-like illness (ILI) examined, as well as the total number of consultations. The later number served as a denominator to derive the proportion of ILI patients among the total number of consultations. Based on historical data from the sentinel surveillance system, the influenza season in Greece typically starts in January and lasts through March or April, with a peak in late winter (usually February).

In addition, all-cause mortality was monitored as part of the European Mortality Monitoring (EuroMoMo) project. The objective of this project is to develop a Europe-wide mortality monitoring system for detecting excess deaths related to possible public health threats across Europe, such as influenza [15].

In Greece, influenza vaccination is offered free of charge each year to people in high-risk groups. For the 2010/11 influenza season, the national immunisation campaign started in October 2010 and recommended the trivalent influenza vaccine to persons with chronic conditions, elderly people aged over 60 years, healthcare workers and caregivers. Unfortunately, a low rate of vaccine uptake was achieved. A telephone survey estimated that, when the influenza epidemic peaked in the community in early February 2011, the vaccination coverage among the general population stood at just 5.9 percent [16].

This report summarises data from influenza surveillance in Greece during the post-pandemic 2010/11 influenza season. We focus on the characteristics of laboratory-confirmed cases who required admission to an ICU, and of those with a fatal outcome, reported until 22 May 2011.

\section{Methods}

Patients, whose data were recorded, were all laboratory-confirmed influenza cases (as determined by realtime RT-PCR) who were admitted to an ICU, as well as those with a fatal outcome.

The data collected for each case, using a standardised form, were: demographic characteristics (age, sex), dates of admission to the hospital and the ICU, the time course of illness including the date of symptom onset, underlying conditions, complications, use of mechanical ventilation support (dates of intubation and extubation), and antiviral treatment.

\section{FIGURE 1}

Epidemic curves based on surveillance data from sentinel influenza-like illness consultation rates, intensive care unit admissions $(n=368)$, and fatal cases $(n=180)$, Greece, 04 October 2010-22 May 2011

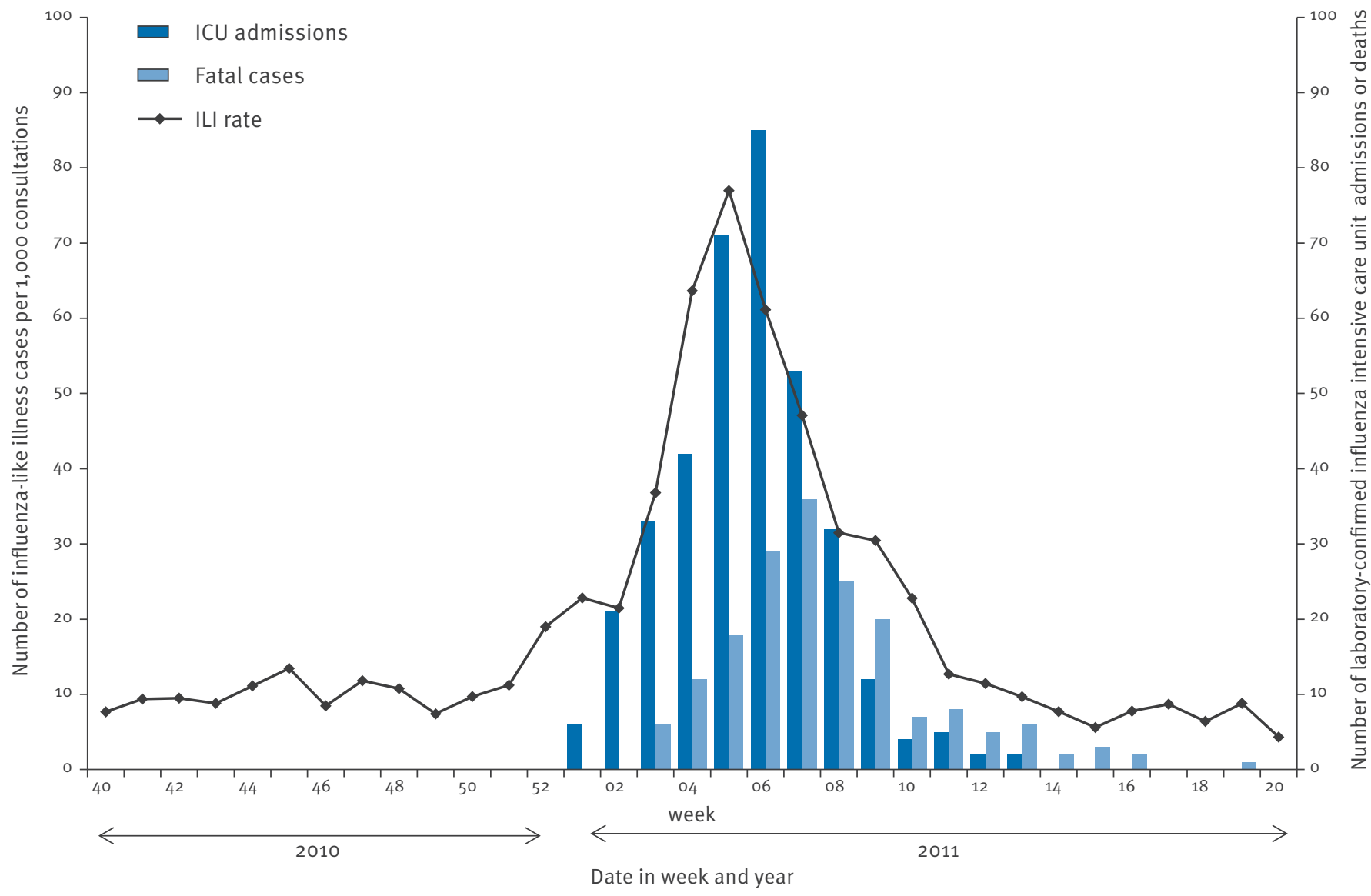


According to the HCDCP's guidelines, physicians needed to maintain a high level of clinical suspicion for influenza and had to consider influenza in the differential diagnosis of cases admitted to an ICU with severe respiratory disease, such as respiratory failure, chronic obstructive pulmonary disease (COPD) exacerbation, or acute respiratory distress syndrome (ARDS). In such cases, laboratory testing of nasopharyngeal swab specimens was strongly recommended.

Fatal cases were defined as those associated with influenza infection, provided that the infection was laboratory-confirmed either before or after death. A definitive causal relationship between influenza infection and death was not routinely sought and/or established.

Age-specific mortality rates were calculated using the estimated age-specific population of Greece for 2010 [17].

As part of virological surveillance, nasopharyngeal swab specimens were sent for testing by sentinel and hospital physicians to one of the two national reference laboratories.

The statistical analysis was carried out using the GNU R software [18].

\section{Results}

Epidemic curve and surveillance results

Figure 1 presents the surveillance results and epidemic curve during the 2010/11 influenza season, based on surveillance data on (i) sentinel ILI, (ii) ICU admissions, and (iii) fatal cases. The sentinel ILI rate followed a typical seasonal pattern with a peak in the fifth week of 2011. The number of ICU admissions and the number of fatal cases followed similar patterns, peaking in the sixth and seventh week of 2011, respectively.

The results of the comparison of the age distribution of the sentinel ILI cases, between the pandemic and the post-pandemic season, were suggestive of a shift to older ages (median age 13 years, range: o to 98 years vs 17 years, range: o to 96 years, pro.001; Figure 2a).

\section{Virological surveillance}

The results of virological surveillance are summarised in Table 1 . In the period between week 402010 and week 20 2011, 13,279 specimens were tested. Of all strains detected, from both sentinel and non-sentinel specimens, $98.2 \%$ were influenza $A$ and $1.8 \%$ influenza $B$ viruses. Of all influenza A strains subtyped, 25 (0.5\%) were $\mathrm{A}\left(\mathrm{H}_{3} \mathrm{~N}_{2}\right)$ while 5,281 (99.5\%) were $\mathrm{A}\left(\mathrm{H}_{1} \mathrm{~N}_{1}\right)_{2} 2009$, indicating that the pandemic influenza $\mathrm{A}\left(\mathrm{H}_{1} \mathrm{~N}_{1}\right)_{2009}$ was by far the predominant strain.

\section{Surveillance of intensive care unit} admissions and fatal cases

Between 8 January 2011 (when the first case was reported) and 22 May 2011, a total of 368 laboratoryconfirmed influenza $\mathrm{A}\left(\mathrm{H}_{1} \mathrm{~N}_{1}\right) 2009$ cases admitted to an
ICU were reported to the HCDCP. Of these cases, 220 survived, 144 died, and four were still hospitalised, at the time when data were extracted for analysis $(22$ May 2011). The ICU-related case fatality rate was $39 \%$. Another 36 deaths occurred in patients hospitalised in regular wards. All 180 fatal cases were included in the current analysis. On a general population basis, this corresponds to 15.9 ( $95 \% \mathrm{Cl}: 13.7$ to 18.4 ) fatal cases per million.

All laboratory-confirmed cases with a fatal outcome $(n=180)$, were positive for influenza $A\left(\mathrm{H}_{1} \mathrm{~N}_{1}\right)$ 2009. At the peak of the outbreak, 155 patients were hospitalised at the same time in an ICU.

\section{FIGURE 2}

Age distribution of sentinel influenza-like illness cases $(n=19,120)$, intensive care admissions $(n=662)$, and fatal cases $(n=329)$, influenza seasons 2009/10 and 2010/11, Greece

\section{A. Sentinel influenza-like illness cases}

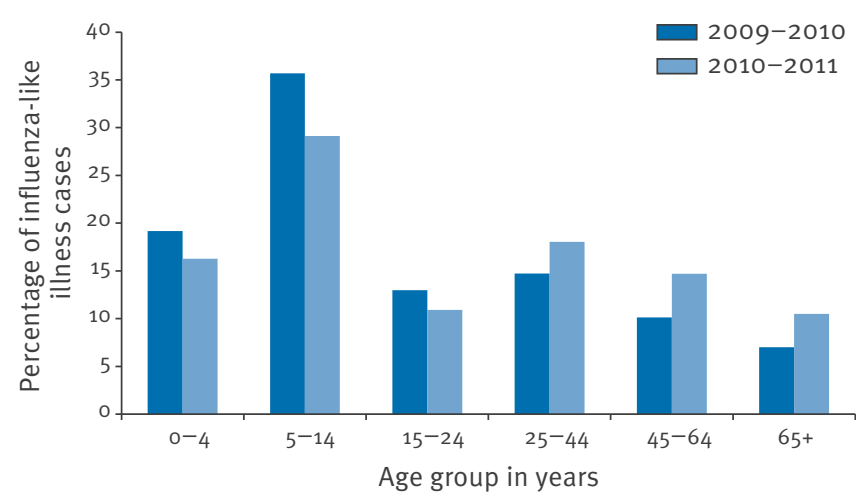

B. Intensive care unit admissions

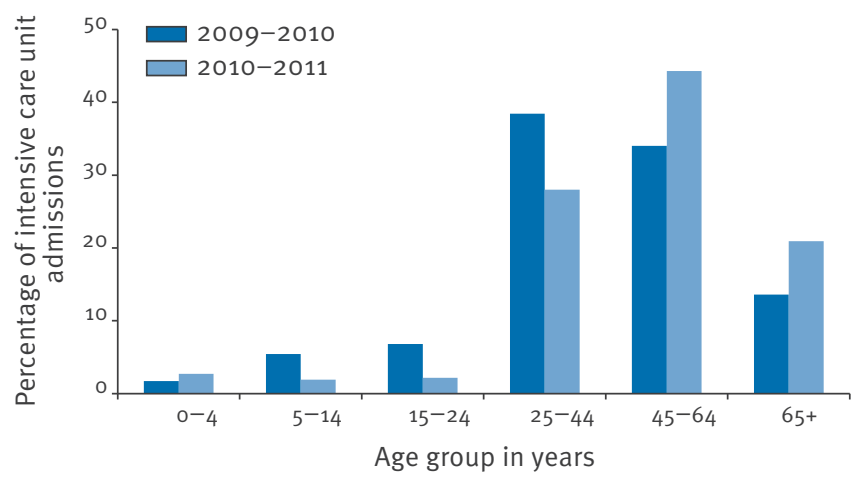

C. Fatal cases

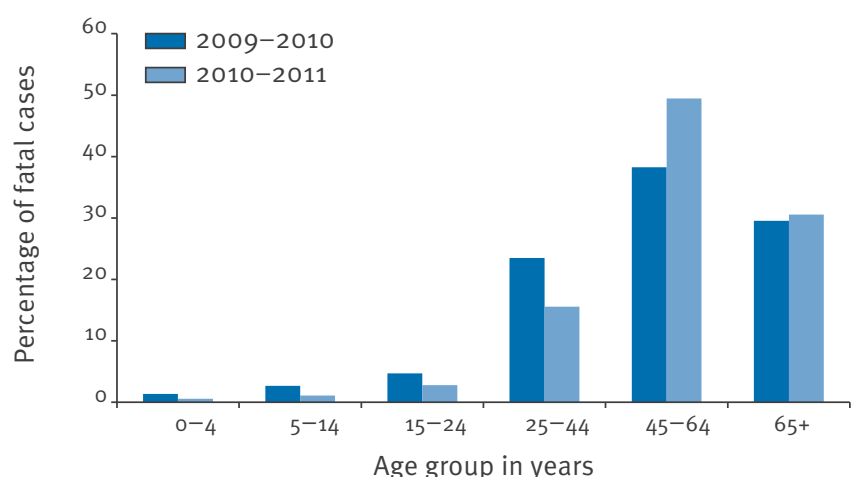


Demographic characteristics

Data on age and sex were available for all cases. The median age of the 368 cases admitted to an ICU was 52 years (range: 3 months to 86 years). Twenty patients (5\%) were children aged 18 years or under, and 77 patients $(21 \%)$ were aged 65 years or older.

The median age of the 180 fatal cases was 56.5 years (range: 2.5 to 96 years). Four of these (2\%) were children aged 18 years or under. The majority of cases with a fatal outcome $(80 \%)$ had been treated in an ICU. Fatal cases treated in an ICU tended to be younger than those treated in the regular wards (median age 56 years, range: 2.5 to 86 years vs 64 years, range: 39 to 96 years, $p<0.001)$

The age group with the highest mortality rate were adults aged between 45 and 64 years, with a population mortality rate of 30.3 persons ( $95 \% \mathrm{Cl}: 24.3$ to 37.3) per million people of the respective age group, followed by the age group of over 65 years with 25.7 persons (95\% Cl: 19.3 to 33.4 ) per million.

The results of the comparison of the age distribution of the ICU admitted cases, as well as the fatal cases, between the pandemic period and the post-pandemic influenza season, were suggestive of a shift toward older age groups ( $p<0.001$ and $p=0.063$, respectively; Figures $2 b \& 2 c)$.
Of the total 368 cases admitted to an ICU, 207 (56\%) were male and 161 (44\%) were female. Among cases with a fatal outcome, 106 (59\%) were male and 74 (41\%) were female. Being male was significantly associated with either admission to an ICU $(p=0.010)$, or death $(p=0.012)$.

Course of disease and antiviral treatment

The time course of illness and antiviral treatment are described in Table 2. Seventeen cases developed influenza-like symptoms while already hospitalised in the ICU for another illness/condition. Three of the 36 fatal cases developed influenza-like symptoms while hospitalised in regular wards. Overall, 357 of the 366 cases with available information (98\%) received antiviral treatment. Of 270 for which data was available, 68 $(25 \%)$ received treatment within 48 hours of symptom onset. The median time from symptom onset to treatment was four days, both for cases admitted to an ICU and for cases with a fatal outcome.

Of the 368 patients admitted to an ICU, 306 (83\%) required mechanical ventilation support for a median of 12 days (range: 0 to 76 ).

Underlying conditions and complications

Patients admitted to an ICU had a median of one underlying condition (118 had no underlying condition, 158 had one, 72 had two, 17 had three, two had four and

\section{TABLE 1}

Results of virological surveillance for influenza, Greece, 04 October 2010-22 May 2011

\begin{tabular}{|c|c|}
\hline & Number of specimens (\%) \\
\hline Specimens positive for influenza & $5,403(40.7 \%)^{\mathrm{a}}$ \\
\hline Specimens positive for influenza type $A$ & $5,306(98.2 \%)^{b}$ \\
\hline Specimens positive for $\mathrm{A}\left(\mathrm{H}_{1} \mathrm{~N}_{1}\right)$ - non pandemic & $0(0.0 \%)^{c}$ \\
\hline Specimens positive for $\mathrm{A}\left(\mathrm{H}_{3} \mathrm{~N}_{2}\right)$ & $25(0.5 \%)^{c}$ \\
\hline Specimens positive for $\mathrm{A}\left(\mathrm{H}_{1} \mathrm{~N}_{1}\right)_{2009}$ & $5,281(99.5 \%)^{c}$ \\
\hline Specimens positive for influenza type B & $97(1.8 \%)^{\mathrm{b}}$ \\
\hline Specimens negative for influenza & $7,876(59.3 \%)^{a}$ \\
\hline Total number of specimens tested & $13,279(100.0 \%)^{a}$ \\
\hline
\end{tabular}

a Percentage is calculated using total number of specimens tested as denominator.

b Percentage is calculated using number of specimens positive for influenza as denominator.

Percentage is calculated using number of specimens positive for influenza type $A$ as denominator.

\section{TABLE 2}

Time course of care-measures for patients with influenza, Greece, 04 October 2010-22 May 2011

\begin{tabular}{|l|c|c|}
\multirow{2}{*}{ Symptom onset to hospital admission } & Intensive care unit admissions & Fatal cases \\
\cline { 2 - 3 } & $\mathbf{2}$ & Median number of days (IQR) \\
\hline Hospitalisation to intensive care unit admission & $\mathbf{3}(1-5)$ & $\mathbf{1}(0-5)$ \\
\hline Duration of stay in intensive care unit & $\mathbf{1}(0-2)$ & $\mathbf{1 2}(6-24)$ \\
\hline Duration of mechanical ventilation & $\mathbf{1 3}(6-24)$ & $\mathbf{1 1}(5-21)$ \\
\hline Symptom onset to start of antiviral treatment & $\mathbf{4}(2-7)$ & $\mathbf{4}(\mathbf{2}-7)$ \\
\hline
\end{tabular}


one had five). Underlying disease was equally distributed between the sexes; higher rates were observed in older age groups such as the group aged 60 years and older ( $p<0.001$ ) (Figure 3).

Fatal cases had also a median of one underlying condition. Two of four children with a fatal outcome had no documented underlying condition, while the majority of cases over the age of 60 years (69 of $74,93 \%$ ) had at least one underlying condition. The number of underlying conditions in influenza patients admitted to ICUs or influenza fatal cases, stratified by age group, is shown in Figure 3.

Metabolic disease (including diabetes) and chronic respiratory disease were the most commonly reported long-term underlying conditions among patients

\section{FIGURE 3}

Number of underlying conditions in influenza patients admitted to intensive care units $(n=368)$ or influenza fatal cases $(n=180)$, stratified by age group, Greece, 04 October 2010-22 May 2011

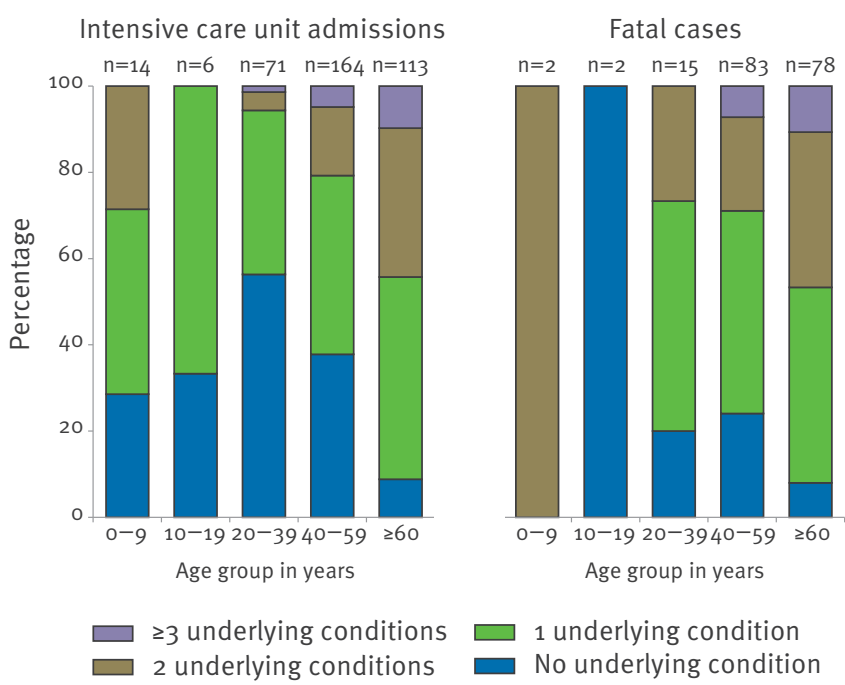

admitted to an ICU, while immunosuppresion and chronic cardiovascular disease were the most commonly reported comorbidities among fatal cases (Table 3).

In children ( $\leq 18$ years), the most commonly reported comorbidity was neurological disease (nine of 20 for children admitted to an ICU and two of four for children with a fatal outcome).

Nine pregnant women required admission to an ICU for influenza. They all had no other risk factors. No death occurred in this group.

Morbid obesity was present in 30 of 358 cases ( $8 \%$ ) admitted to an ICU and 18 cases of 173 (10\%) with a fatal outcome.

The most commonly reported severe complication of influenza was pneumonia ( 265 cases, $>90 \%$ viral) followed by the development of ARDS (250 cases).

\section{Discussion}

The burden of severe disease in the first post-pandemic influenza season in Greece was higher than originally expected. The sentinel ILI epidemic curve for this season started around the time that regular influenza season begins in Greece, which is two months later in the winter than the pandemic autumn wave. The epidemic curve for this season was similar in shape and approximately three quarters the size of that observed during the pandemic period [3]. However, when compared with previous influenza seasons (from 2004 onwards) its peak was significantly higher [19]. Regarding the time distribution of ICU admissions, it followed a curve with a peak one week later than the peak of the sentinel surveillance system's curve. This finding is consistent with the fact that increased demand for hospital care usually lags behind the ILI consultation rates by one to two weeks. In our series, the average time from symptom onset to ICU admission was four days.

\section{TABLE 3}

Distribution of underlying medical conditions in influenza patients admitted to intensive care units (n=368) or influenza fatal cases $(\mathrm{n}=180)$, Greece, 04 October 2010-22 May 2011

\begin{tabular}{|l|c|c|}
\hline Underlying condition ${ }^{\mathrm{a}}$ & $\begin{array}{c}\text { Proportion of intensive care unit admissions } \\
\mathrm{n} / \mathrm{N}^{\mathrm{b}}(\%)\end{array}$ & $\begin{array}{c}\text { Proportion of fatal cases } \\
\mathrm{n} / \mathrm{N}^{\mathrm{b}}(\%)\end{array}$ \\
\hline Chronic respiratory disease & $75 / 348(22 \%)$ & $39 / 168(23 \%)$ \\
\hline Chronic cardiovascular disease & $70 / 353(20 \%)$ & $17 / 171(30 \%)$ \\
\hline Chronic renal / liver disease & $12 / 342(4 \%)$ & $\mathbf{1 0} / 163(6 \%)$ \\
\hline Metabolic disease & $86 / 353(24 \%)$ & $54 / 171(27 \%)$ \\
\hline Immunosuppression & $56 / 342(16 \%)$ & $19 / 168(11 \%)$ \\
\hline Neurological / neuromuscular disease & $28 / 346(8 \%)$ & $18 / 173(10 \%)$ \\
\hline Morbid obesity (body mass index $\geq 40)$ & $30 / 358(8 \%)$ & $0 / 180(0 \%)$ \\
\hline Pregnancy & $9 / 368(2 \%)$ & 5 \\
\hline
\end{tabular}

a Cases could have more than one underlying medical condition.

b Total number of cases or patients for which data were available. 
In contrast to ILI, a much higher peak in the distribution of both ICU admissions and fatal cases was observed this season compared to the pandemic period 20092010. Nevertheless, data from the EuroMoMo surveillance system operating in Greece did not show any excess all-cause mortality in 2011 up to the end of May [19], as during the pandemic period.

Similar to what happened in the UK in December 2010, during the first weeks of the 2010/11 influenza season, a paradoxically higher number of admissions to ICUs was reported, while the ILI rate was low. Stress on higher-level healthcare facilities when community consultation rates are low is unusual, but this was consistent with the characteristics of the pandemic influenza $A\left(\mathrm{H}_{1} \mathrm{~N}_{1}\right) 2009$ strain that causes mild disease in the majority of cases but very severe disease in a very few [20].

The total number of ICU admissions was higher during the post-pandemic influenza season than during the pandemic period and there was more pressure on ICUs. The maximum number of patients hospitalised at the same time in an ICU (155 in the post-pandemic influenza season $2010 / 11$ vs 70 during the pandemic period) corresponds to an approximate $24 \%$ coverage of the total ICU bed capacity in the country. However, it is difficult to compare with previous influenza seasons, due to the lack of surveillance for severe influenza cases during these seasons. There was no significant difference in the ICU related case-fatality rates between the two seasons (43\% for the pandemic 2009-2010 period vs $39 \%$ for the post-pandemic $2010 / 11$ season).

The median age of cases admitted to an ICU was significantly higher than during the pandemic period. This shift to older ages may offer at least a partial explanation for the higher number of fatal cases during this influenza season, since older age has been found to be independently associated with a worse outcome [21].

The most common comorbidities were metabolic and chronic respiratory disease for cases admitted to an ICU, while cardiovascular disease and immunosuppression were most frequently reported among fatal cases. These findings are consistent with published reports from other countries $[22,23]$.

Another noteworthy finding is the presence of neurodevelopmental disease in the paediatric ICU patients. This is in line with data from the pandemic period in Greece, when a large proportion of children and teenagers with a fatal outcome suffered neurological disorders [3]. The findings of a United States (US) study also identify pre-existing neurodevelopmental disorders, as one of the most noticeable risk factors among children who died from pandemic influenza [24].

The delay in initiation of antiviral treatment may be attributed to the fact that patients generally do not seek medical care immediately (median time from onset of symptoms to hospital admission was three days). Data regarding the time course of antiviral treatment are comparable with those reported in a number from other studies [25-27].

Furthermore, the prevalence of morbid obesity both in ICU admitted cases ( $8 \%$ ) and in fatal cases (10\%) is much higher than the estimate for the adult population of Greece ( $<1 \%$ ) [28]. This finding is in agreement with data from other studies [25,29-31], which identify morbid obesity as an independent risk factor for severity of disease associated with the $\mathrm{A}\left(\mathrm{H}_{1} \mathrm{~N}_{1}\right) 2009$ strain.

The population cumulative mortality in the elderly $(\geq 65$ years) was lower than in adults aged 45 to 64 years. Though not statistically significant, this could be the result of lower susceptibility of the oldest group to infection according to serology data for pre-existing immunity from other countries [32].

In conclusion, this report summarises the experience of Greece, during the first post-pandemic influenza season. In contrast to what was observed in countries of the southern hemisphere during this season [33], our data suggest that the severity of clinical illness -as measured by the number of patients admitted to the ICUs, the overall population mortality rate, and the impact on the healthcare system- was comparable or even higher in the first post-pandemic than in the pandemic influenza season. Though there are inherent difficulties in comparing the experiences in diverse countries with varying surveillance systems, sharing data is strongly recommended in order to achieve an improved understanding and capture the range of potential outcomes due to laboratory-confirmed influenza [34]. However, the objectives of severe-end influenza surveillance need to be harmonised across European countries in order to obtain comparable data and facilitate a better design of timely interventions in case of more virulent strains.

Funding information

This work was funded by the Hellenic Centre for Disease Control and Prevention (HCDCP) as part of its surveillance mission; HCDCP is funded by the Hellenic Ministry of Health and Social Solidarity.

\section{${ }^{\star}$ Erratum:}

At the moment of publication, the name of A Andreopoulou was left out of the list of authors. This mistake was corrected on 04 November 2011. We apologise to the authors.

\section{References}

1. Panagiotopoulos T, Bonovas S, Danis K, Iliopoulos D, Dedoukou X, Pavli A, et al. Cluster of new influenza A $\left(\mathrm{H}_{1} \mathrm{~N}_{1}\right)$ cases in travellers returning from Scotland to Greece community transmission within the European Union? Euro Surveill. 2009;14(21):pii=19226. Available from: http://www. eurosurveillance.org/ViewArticle.aspx?Articleld=19226

2. Lytras T, Theocharopoulos G, Tsiodras S, Mentis A, Panagiotopoulos T, Bonovas S, et al. Enhanced surveillance of 
influenza $A\left(\mathrm{H}_{1} \mathrm{~N}_{1}\right) v$ in Greece during the containment phase. Euro Surveill. 2009;14(29):pii=19275. Available from: http:// www.eurosurveillance.org/ViewArticle.aspx?Articleld=19275

3. Athanasiou M, Lytras T, Spala G, Triantafyllou E, Gkolfinopoulou K, Theocharopoulos G, et al. Fatal cases associated with pandemic influenza $A\left(\mathrm{H}_{1} \mathrm{~N}_{1}\right)$ reported in Greece. PLoS Curr. 2010;2:RRN1194.

4. Centers for Disease Control and Prevention (CDC). Deaths and hospitalizations related to 2009 pandemic influenza $A\left(\mathrm{H}_{1} \mathrm{~N}_{1}\right)$ Greece, May 2009 - February 2010. MMWR Morb Mortal Wkly Rep. 2010;59(22):682-6.

5. Sypsa V, Bonovas S, Tsiodras S, Baka A, Efstathiou P, Malliori $M$, et al. Estimating the disease burden of 2009 pandemic influenza $\mathrm{A}\left(\mathrm{H}_{1} \mathrm{~N}_{1}\right)$ from surveillance and household surveys in Greece. PLoS One. 2011;6(6):e20593.

6. Nikolopoulos G, Bagos P, Lytras T, Bonovas S. An ecological study of the determinants of differences in 2009 pandemic influenza mortality rates between countries in Europe. PLoS One. 2011;6(5):e19432.

7. Tsiodras S, Sypsa V, Hatzakis A. The vaccination campaign against 2009 pandemic influenza $A\left(\mathrm{H}_{1} \mathrm{~N}_{1}\right)$ and its continued importance in view of the uncertainty surrounding the risk associated with the pandemic. Euro Surveill. 2010;15(3):pii=19468. Available from: http://www. eurosurveillance.org/ViewArticle.aspx?Articleld=19468

8. Rizzo C, Bella A, Viboud C, Simonsen L, Miller MA, Rota MC, et al. Trends for influenza-related deaths during pandemic and epidemic seasons, Italy, 1969-2001. Emerg Infect Dis. 2007;13(5):694-9.

9. Jackson C, Vynnycky E, Mangtani P. Estimates of the transmissibility of the 1968 (Hong Kong) influenza pandemic: evidence of increased transmissibility between successive waves. Am J Epidemiol. 2010;171(4):465-78.

10. Health Protection Agency (HPA). HPA Weekly National Influenza Report - Summary of UK surveillance of influenza and other seasonal respiratory illnesses. 9 December 2010 - Week 49 London: HPA. Available from: http://www.hpa.org.uk/webc/ HPAwebFile/HPAweb_C/1287146267647

11. Health Protection Agency (HPA). HPA Weekly National Influenza Report - Summary of UK surveillance of influenza and other seasonal respiratory illnesses. 16 December 2010 - Week 50. London: HPA. Available from: http://www.hpa.org.uk/webc/ HPAwebFile/HPAweb_C/1287146386672

12. Health Protection Agency (HPA). HPA Weekly National Influenza Report - Summary of UK surveillance of influenza and other seasonal respiratory illnesses. 23 December 2010 - Week 51 London: HPA. Available from: http://www.hpa.org.uk/webc/ HPAwebFile/HPAweb_C/1287146883984

13. Health Protection Agency (HPA). HPA Weekly National Influenza Report - Summary of UK surveillance of influenza and other seasonal respiratory illnesses. 30 December 2010 - Week 52. London: HPA. Available from: http://www.hpa.org.uk/webc/ HPAwebFile/HPAweb_C/1287147913387

14. Health Protection Agency (HPA). HPA Weekly National Influenza Report - Summary of UK surveillance of influenza and other seasonal respiratory illnesses. 6 January 2011 - Week 1. London: HPA. Available from: http://www.hpa.org.uk/webc/ HPAwebFile/HPAweb_C/1287148330414

15. Kanieff M, Rago G, Minelli G, Lamagni T, Sadicova O, Selb J, et al. The potential for a concerted system for the rapid monitoring of excess mortality throughout Europe. Euro Surveill. 2010;15(43):pii=19697. Available from: http://www. eurosurveillance.org/ViewArticle.aspx?Articleld=19697

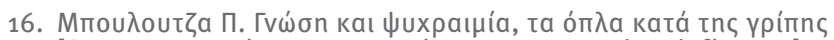
[Awareness and composure, the weapons against influenza]. Kathimerini. Greek. 20 Feb 2011. Available from: http://news. kathimerini.gr/4dcgi/_w_articles_ell_1_20/02/2011_433393

17. Hellenic Statistical Authority. Estimated population by sex and 5-year age groups on 1st January (Years 1991-2010). [Accessed 26 Oct 2011]. Available from: http://www.statistics. $\mathrm{gr} / \mathrm{p}$ ortal/page/portal/ESYE/PAGE-themes?p_param=A1605\&r_ param $=$ SPO18\&y_param $=2010 \_00 \&$ mytabs $=0$

18. The R Project for Statistical Computing. [Accessed 26 Oct 2011]. Available from: http://www.gnu.org/s/r/

19. Hellenic Centre for Disease Control and Prevention (HCDCP), Department of Epidemiological Surveillance and Intervention.

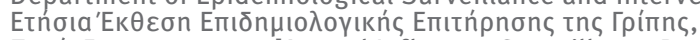
Пєрíoঠoৎ 2010-2011 [Annual Influenza Surveillance Report, Season 2010-2011]. HCDCP. Greek. [Accessed 26 Oct 2011]. Available from: http://www.keelpno.gr/images/stories/ keelpno/Tm_Epidimiologias/annual_report2011.pdf

20. Perez-Padilla R, de la Rosa-Zamboni D, Ponce de Leon S Hernandez M, Quinones-Falconi F, Bautista E, et al. Pneumonia and respiratory failure from swine-origin influenza $A\left(\mathrm{H}_{1} \mathrm{~N}_{1}\right)$ in Mexico. N Engl J Med. 2009;361(7):680-9.
21. ANZIC Influenza Investigators, Webb SA, Pettilä V, Seppelt I, Bellomo R, Bailey M, et al. Critical care services and 2009 $\mathrm{H}_{1} \mathrm{~N}_{1}$ influenza in Australia and New Zealand. N Engl J Med. 2009;361(20):1925-34.

22. Wilking H, Buda S, von der Lippe E, Altmann D, Krause G, Eckmanns T, et al. Mortality of 2009 pandemic influenza $\mathrm{A}\left(\mathrm{H}_{1} \mathrm{~N}_{1}\right)$ in Germany. Euro Surveill. 2010;15(49): $\mathrm{pii}=19741$. Available from: http://www.eurosurveillance.org/ViewArticle. aspx?Articleld $=19741$

23. Jain S, Kamimoto L, Bramley A, Schmitz AM, Benoit SR, Louie J, et al. Hospitalized patients with $2009 \mathrm{H}_{1} \mathrm{~N}_{1}$ influenza in the United States, April-June 2009. N Engl J Med. 2009;361(20):1935-44.

24. Centers for Disease Control and Prevention (CDC). Surveillance for pediatric deaths associated with 2009 pandemic influenza A $\left(\mathrm{H}_{1} \mathrm{~N}_{1}\right)$ virus infection - United States, April-August 2009. MMWR Morb Mortal Wkly Rep. 2009;58(34):941-7.

25. Santa-Olalla Peralta P, Cortes-Garcia M, Vicente-Herrero M, Castrillo-Villamandos C, Arias-Bohigas P, Pachon-del Amo I, et al. Risk factors for disease severity among hospitalised patients with 2009 pandemic influenza $A\left(\mathrm{H}_{1} \mathrm{~N}_{1}\right)$ in Spain, April-December 2009. Euro Surveill. 2010;15(38): pii=19667. Available from: http://www.eurosurveillance.org/ViewArticle. aspx?Articleld $=19667$

26. Donaldson LJ, Rutter PD, Ellis BM, Greaves FE, Mytton OT, Pebody RG, et al. Mortality from pandemic A/H1N1 2009 influenza in England: public health surveillance study. BMJ. 2009;339:b5213.

27. Martin-Loeches I, Rodriguez A, Bonastre J, Zaragoza R, Sierra $R$, Marques $A$, et al. Severe pandemic $\left(\mathrm{H}_{1} \mathrm{~N}_{1}\right) v$ influenza $A$ infection: report on the first deaths in Spain. Respirology. 2011;16(1):78-85.

28. Panagiotakos DB, Pitsavos C, Chrysohoou C, Risvas G, Kontogianni MD, Zampelas A, et al. Epidemiology of overweight and obesity in a Greek adult population: the ATTICA Study. Obes Res. 2004;12(12):1914-20.

29. Centers for Disease Control and Prevention (CDC). Hospitalized patients with novel influenza $A\left(\mathrm{H}_{1} \mathrm{~N}_{1}\right)$ virus infection California, April-May 2009. MMWR Morb Mortal Wkly Rep. 2009;58(19):536-41.

30. Centers for Disease Control and Prevention (CDC). Intensivecare patients with severe novel influenza $A\left(\mathrm{H}_{1} \mathrm{~N}_{1}\right)$ virus infection - Michigan, June 2009. MMWR Morb Mortal Wkly Rep. 2009;58(27):749-52.

31. Morgan OW, Bramley A, Fowlkes A, Freedman DS, Taylor TH, Gargiullo P, et al. Morbid obesity as a risk factor for hospitalization and death due to 2009 pandemic influenza A (H1N1) disease. PLoS One. 2010;5(3):e9694.

32. Miller E, Hoschler K, Hardelid P, Stanford E, Andrews N, Zambon $\mathrm{M}$. Incidence of 2009 pandemic influenza $\mathrm{A} \mathrm{H}_{1} \mathrm{~N}_{1}$ infection in England: a cross-sectional serological study. Lancet. 2010;375(9720):1100-8.

33. Bandaranayake D, Jacobs $M$, Baker M, Hunt D, Wood T, Bissielo A, et al. The second wave of 2009 pandemic influenza $A\left(\mathrm{H}_{1} \mathrm{~N}_{1}\right)$ in New Zealand, January-October 2010. Euro Surveill. 2011;16(6):pii=19788. Available from: http://www. eurosurveillance.org/ViewArticle.aspx?Articleld=19788

34. Kelly HA, Cowling BJ. Insights from Europe related to pandemic influenza $A\left(\mathrm{H}_{1} \mathrm{~N}_{1}\right) 2009$ have international relevance. Euro Surveill. 2011;16(26): $i i=19899$. Available from: http://www. eurosurveillance.org/ViewArticle.aspx?Articleld=19899 